\title{
Prevalence and Associated Factors of Acute Malnutrition Among 6-59 Month Children in Adi-Harush and Hitsats Refugee Camps in Tigray Region Northern Ethiopia, 2017
}

\author{
Hagos Brhane ${ }^{1}$, Bekri Mohammed ${ }^{2}$, Hedja Yenus Yeshita ${ }^{3}$, Kedir Abdela Gonete ${ }^{2, *}$ \\ ${ }^{1}$ Ayder Health Center, Mekele, Ethiopia \\ ${ }^{2}$ Department of Human Nutrition, Institute of Public Health, College of Medicine and Health sciences, University of Gondar, Gondar, \\ Ethiopia \\ ${ }^{3}$ Department of Reproductive Health, Institute of Public Health, College of Medicine and Health sciences, University of Gondar, Gondar, \\ Ethiopia
}

Email address:

hagosbrhane29@gmail.com (H. Brhane), bekrim12@gmail.com (B. Mohammed), kedijayenus@gmail.com (H. Y. Yeshita), kedirabdela33@gmail.com (K. A. Gonete)

${ }^{*}$ Corresponding author

\section{To cite this article:}

Hagos Brhane, Bekri Mohammed, Hedja Yenus Yeshita, Kedir Abdela Gonete. Prevalence and Associated Factors of Acute Malnutrition Among 6-59 Month Children in Adi-Harush and Hitsats Refugee Camps in Tigray Region Northern Ethiopia, 2017. American Journal of Life Sciences. Vol. 6, No. 5, 2018, pp. 57-64. doi: 10.11648/j.ajls.20180605.11

Received: November 2, 2018; Accepted: December 4, 2018; Published: January 16, 2019

\begin{abstract}
Background: Wasting is characterized by low weight for height and it is common in developing countries. Wasted children have lower resistance to infection, impaired learning ability and reduce economic productivity. Objective: The aim of this study was to assess the prevalence and associated factors of acute malnutrition among children aged 6-59 months in Adiharush and Hitsats Eritrean refugee camps. Methods: A community-based cross-sectional study was conducted from March 1 to April 15/2017, at Adi-Harush and Hitsats Refugee Camps. A total of 471 subjects were selected using the multi-stage sampling technique and Pre-tested and structured questionnaire was used to collect data. Multivariable logistic regression analysis was fitted to identify factors associated with acute malnutrition. Adjusted Odds Ratio (AOR) with the corresponding 95\% Confidence Interval (CI) was used to show the strength of associations and variables with p-values of $<0.05$ were considered as statistically significant. Results: The finding of this study revealed that $37 \%, 21.6 \%$ and $11 \%$ of children were stunted, underweight and wasted respectively. Child age 48-57 months (AOR=0.12, 95\%CI: 0.03-0.39), frequency of feeding less than 3 times a day $(\mathrm{AOR}=1.95,95 \% \mathrm{CI}$ : 1.001-3.8) and not exclusive breast feeding $(\mathrm{AOR}=2.51,95 \% \mathrm{CI}: 1.17-5.40)$ were significantly associated with wasting. Conclusion: The prevalence of wasting (11\%) in the study area is very high. Frequency of feeding, exclusive breast-feeding and child age were significantly associated with wasting. Improve community health education for pregnant and lactating mothers and giving exclusive breast feeding for the children's are one of the prevention mechanisms for child wasting.
\end{abstract}

Keywords: Acute Malnutrition, Ethiopia, Under Five Children, Adi-harush and Hitsats

\section{Introduction}

Maternal and child under nutrition contributes to more than one-third of child deaths, more than $10 \%$ of the total global disease burden and is the single largest contributor to child mortality $[1,2]$. Acute malnutrition (wasting) is one of the three main types of under nutrition affecting potentially all categories of the population, especially vulnerable groups such as children under five, pregnant and lactating women, and people living with a disease or chronic illness [3].

Wasting (low weight-for-height) is a measure of acute under nutrition that represents the failure to receive adequate nutrition in the period immediately before the survey. Children are most vulnerable to malnutrition in developing countries because of low dietary intakes, lack of appropriate 
care, and inequitable distribution of food within the households [4]. Displacement also affects food security, especially in the initial stages before assistance can be provided [5].

Even though under-nutrition remains a major public health problem in developing countries, it is more apparent in refugee populations who are displaced from war town areas to neighboring countries [6]. The weight-for-height indexes measure body mass in relation to body height or length and describe current nutritional status. Children whose Z-score is below minus two standard deviations ( -2 SD) from the median of the reference population are considered as thin (wasted) or acutely undernourished [7, 8].

Globally in 2016, wasting continued to threaten the lives of an estimated 7.7 per cent children under 5 and 52 million children under five in the world today are facing a struggle between life and death due to a condition that is preventable. These 52 million mainly living in sub-Saharan Africa and the developing regions of Asia and they are at risk of dying from a mix of hunger and disease that has caused them to develop acute malnutrition $[3,8]$.

Excluding those from the West Bank and Gaza, the number of refugees in 2014 was 14.4 million or 6 percent of the international migrants in 2013. About 86 percent of the refugees are hosted by developing countries [9].

According to EDHS (Ethiopian Demographic Health Survey) $2016,38 \%$ of children under age 5 in Ethiopia are stunted or too short for their age, $18 \%$ severely stunted, $10 \%$ are wasted or too thin for their height, including 3\% who are severely wasted. Also $24 \%$ of the children are underweight or too thin for their age, with 7\% severely underweight [8].

Wasting does not only cause high mortality and morbidity, but also leads to physical and mental impairment in children. The health and physical consequences of prolonged states of malnourishment among children are delays in physical growth, drops in intellectual quotients, poor cognitive ability, decreased economic productivity, reduced reproductive performance, poor school performance and achievement, greater behavioral problems, deficient social skills, and susceptibility to diseases [10-18]. Although different programs and strategy have been launched as intervention for alleviating the acute malnutrition (wasting) of under five age children in Ethiopia, the $10 \%$ rate of the prevalence noted in 2011 remained the same until the 2016 EDHS. Therefore, the main aim of this study was to assess the prevalence and associated factors of acute malnutrition among children below five years of age in Adi-harush and Hitsats refugee camps in Tigray Region, north Ethiopia [8, 21].

\section{Methods}

\subsection{Study Setting and Design}

A multi-stage cross-sectional study was conducted on mother-child pair in Adi- harush and Hitsats refugee camps from March to April, 2017. There are four Eritrean refugee camps in the Western Zone of Tigray Regional State located
1055-1166 km from Addis Ababa and 290-391 km from Mekele town. The total refugee populations are 48,000 with $52 \%$ male. There were 1881 under 5 children in the two selected refugee camps. At the moment, one health center was serving a camp of each refugee.

\subsection{Study Participants and Sampling Procedure}

All children's who were 6-59 months of age and had lived at four refugee camps for at least 01 months were included in the study, while children whose mothers were too ill to communicate verbally and children with physical impairments were excluded.

The sample size was calculated by using the single population proportion formula with the assumptions of a $95 \%$ confidence interval, $5 \%$ margin of error, $24.6 \%$ prevalence of acute malnutrition [22], $10 \%$ non-response rate and 1.5 design effect was anticipated to obtain the final sample size of 471 .

A multi-stage stratified sampling followed by a systematic random sampling technique was employed to reach the study subjects and 2 refugee camps (Adi-harush and Hitsats) were selected using lottery method. The number of study participants was allocated to each refugee camp in proportion to population size using the food ration registration as a sampling frame. Infant-mother pairs were selected by using the systematic random sampling technique after giving codes to each house-hold which had 6- 59 month children. The first participant was selected using the lottery method and continued by selecting every $k^{\text {th }}$ mother until our sample size was attained.

\subsection{Data Collection Procedure and Management}

A structured questionnaire and anthropometric measurement for nutritional status were used to collect the data and the questionnaires were addressed through the face to face interview technique. The questionnaire was initially prepared in English and translated into the local language, Tigrigna. The standardized anthropometry measuring scale was used to assess the physical growth and nutritional status of the children; measurements of height and weight were taken for all children. The measurement of weight was done with the Salter scale and beam balance with specified age categories. During the measurement, the children wore minimum/light clothes, took shoes and the reading was to the nearest $0.1 \mathrm{~kg}$. Recumbent length measurement was taken for children under two years of age, while for children above two years stature was measured in a standing position. During height measurement, the children's were at Frankfurt position and at least five places were touched (occipital, shoulders, buttock, calf and, heels) the standing stadio-meter.

Six diploma and two BSc graduate nurses who are proficient in the local language were assigned for data collection and supervision respectively. Two day intensive training was given to both parties on matters relating to the aims of the questionnaire and the techniques of interview. Data validity and reliability was maintained through close 
supervisions by the principal investigators and trained supervisors. To minimize systematic errors, height and weight of children were taken twice by the same person and the average value of the measures was taken for final analysis. The collected data were reviewed and checked for completeness and consistency.

\subsection{Statistical Analysis}

The collected data was coded and entered in to EPI INFO version 7 and exported to SPSS version 20.0 for further analysis. Anthro nutritional software was used to measure and determine the indices of the anthropometric data with $\mathrm{Z}$ score. Descriptive statistics, such as frequencies, proportions and cross-tabs were used to present data. Both bi-variable and multivariable binary logistic regression analysis were performed. In the bi-variable analysis, variables with $\mathrm{p}$-value of $<0.2$ were considered into the final model and Adjusted Odds Ratio (AOR) with 95\% Confidence Interval (CI) was used to show the presence and strength of association. Finally, p-value of less than 0.05 in the multivariable logistic regression model was used to identify variables significantly associated with acute malnutrition.

\section{Results}

\subsection{Socio Demographic and Economic Characteristics}

Of the whole, 471 mothers-child pairs participated with a $100 \%$ response rate. Most of the participants (92.6\%) were Orthodox Christians and $95.5 \%$ of them were Tigrians. Regarding marital status, $58.6 \%$ of the mothers were married. The mean age of mothers was 26 years $(\mathrm{SD}+5.5)$, and the children were 30.8 months old (SD +13.8$)$. More than half of $(58 \%)$ the mothers were attended grades $1-8$ while $47.5 \%$ of the husbands were grade 9 and above. The majorities $(92.6 \%)$ of the mothers were house wives and $76.6 \%$ of the husbands did not have any jobs (Table 1).

Table 1. Socio-demographic characteristics in Adi-harush and Hitsats Eritrean refugee camps in Tigray region north Ethiopia 2017.

\begin{tabular}{lll}
\hline Variable & Frequency & Percentage\% \\
\hline Religion & & \\
Orthodox & 436 & 92.6 \\
Others & 35 & 7.4 \\
Marital status & & \\
Married & 276 & 58.6 \\
Separated & 169 & 35.9 \\
Others & 26 & 5.5 \\
Educational status of mother & & \\
Un able to read and write & 102 & 21.6 \\
1-8 grade & 273 & 58 \\
$>9$ grade and above & 96 & 20.3 \\
Educational status of fathers & & \\
Un able to read and write & 47 & 10 \\
$1-8$ grade & 200 & 42.5 \\
$9-12$ grade & 224 & 47.5 \\
Occupation of mothers & & 92.6 \\
House wife & 436 & \\
\hline
\end{tabular}

\begin{tabular}{lll}
\hline Variable & Frequency & Percentage\% \\
\hline Others & 35 & 7.4 \\
Occupation of husband & & \\
Private and daily worker & 108 & 23 \\
No work and Student & 361 & 76.6 \\
Occupation of husband & & \\
Private and daily worker & 108 & 23 \\
No work and Student & 361 & 76.6 \\
Monthly income of the family & & \\
Ration only & 262 & 55.6 \\
$<500$ & 53 & 11.3 \\
$500-1000$ & 124 & 26.3 \\
$>1000$ & 32 & 6.8 \\
Male & 239 & 50.7 \\
Female & 232 & 49.3 \\
\hline
\end{tabular}

\subsection{Maternal and Child Care Practice}

Regarding ANC follow ups, $74.9 \%$ of the mothers made 4 and more follow ups, $86.6 \%$ mother was made birth preparedness and $69.9 \%$ delivered at $\mathrm{HC}^{\prime}$ 's (institutional delivery). During pregnancy, $61.4 \%$ of the mothers received extra food and all types of family planning utilization coverage were only $36.5 \%$. Majority of the mothers $(87.5 \%)$ were exclusively breast feed their children. Vitamin A and de-warming supplementations coverage were 90 and $69 \%$ respectively. Regarding health status, $10 \%$ of the children were ill with diarrhea and $16.6 \%$ with ARI in the last two weeks (Table 2).

Table 2. Maternal and child caring practice in Adi-harussh and Hitsats Eritrean refugee camps in Tigray region North Ethiopia 2017.

\begin{tabular}{|c|c|c|}
\hline Variable name & Freq & Percentage $(\%)$ \\
\hline \multicolumn{3}{|l|}{ Age of child } \\
\hline 6-11 months & 39 & 8.3 \\
\hline $12-23$ months & 106 & 22.5 \\
\hline 24-35 months & 134 & 28.5 \\
\hline $36-47$ months & 101 & 21.4 \\
\hline 48-59 months & 90 & 19.3 \\
\hline \multicolumn{3}{|c|}{ Extra food receiving during pregnancy } \\
\hline Yes & 289 & 61.4 \\
\hline No & 182 & 38.6 \\
\hline \multicolumn{3}{|l|}{ Number of PNC follow ups } \\
\hline No seen & 128 & 27.2 \\
\hline $1-3$ times & 236 & 50.1 \\
\hline$>=4$ times & 107 & 22.5 \\
\hline \multicolumn{3}{|l|}{ Vitamin A supplementation } \\
\hline Yes & 424 & 90 \\
\hline No & 47 & 10 \\
\hline \multicolumn{3}{|l|}{ MUAC of mothers } \\
\hline$<23 \mathrm{~cm}$ & 151 & 32 \\
\hline$>23 \mathrm{~cm}$ & 320 & 67.9 \\
\hline \multicolumn{3}{|c|}{ Ill with diarrhea in the last two weeks } \\
\hline Yes & 47 & 10 \\
\hline No & 424 & 90 \\
\hline \multicolumn{3}{|l|}{ ANC follow up times } \\
\hline$<$ One times ANC follow up & 14 & 3 \\
\hline 2-3 times ANC follow up & 104 & 22.1 \\
\hline$>=4$ times ANC follow up & 353 & 74.9 \\
\hline
\end{tabular}




\begin{tabular}{lll}
\hline Variable name & Freq & Percentage (\%) \\
\hline Birth preparedness & & \\
Yes & 408 & 86.6 \\
No & 134 & 23 \\
Birth place & & \\
Health facility & 329 & 69.9 \\
Home & 142 & 30 \\
Complimentary feeding counseling & & \\
Yes & 411 & 87.3 \\
No & 60 & 12.7 \\
Family planning utilization & & \\
Yes & 172 & 36.5 \\
No & 299 & 63.5 \\
Exclusive breast feeding practice & & \\
Yes & 412 & 87.5 \\
No & 59 & 12.5 \\
Ill with ARI & & \\
Yes & 78 & 16.6 \\
No & 393 & 83.4 \\
\hline
\end{tabular}

\subsection{Environmental Factor}

Based on our findings, $38 \%$ used less than $20 \mathrm{~L}, 37 \%$ use $20-50 \mathrm{~L} /$ dayand the remaining $25 \%$ use more than 50 $\mathrm{L} /$ day/cap of water. Latrine utilization coverage, hand washing practice after using latrine, after handling waste, and before feeding were $91 \%, 92,76$ and $91 \%$ respectively (Table 3).
Table 3. Environmental related factors in Adi-harush and Hitsats refugee camp in Tigray region north Ethiopia 2017.

\begin{tabular}{lll}
\hline Variable name & Freq & Percentage (\%) \\
\hline Water served per day & & \\
$<20$ liter & 177 & 37.6 \\
20-50 liters & 173 & 36.7 \\
$>50$ litter & 121 & 25.7 \\
Latrine utilization coverage & & \\
Yes & 430 & 91.3 \\
No & 41 & 8.7 \\
Hand washing after handling waste & & \\
Yes & 356 & 75.6 \\
No & 115 & 24.4 \\
Hand washing after using latrine & & \\
Yes & 433 & 91.9 \\
No & 38 & 8.1 \\
\hline
\end{tabular}

Prevalence of Malnutrition

The prevalence of malnutrition in the study area was $11 \%$ (95\%CI: 8.2-13.8\%) for wasting, $21 \%$ for under weight and $37 \%$ for stunting. The prevalence of wasting was higher (13.8\%) among male than female children. Unlike wasting and underweight, stunting was slightly higher in female than male children (37.9). Sever stunting was above the WHO standards and remains a critical problem in the area and needs special attention to prevent morbidity and mortality relating to nutritional status (Table 4).

Table 4. Nutritional status of male and female category 6-59 month children in Adi-harush and Hitsats Eritrea refugee camp in Tigray region north Ethiopia in 2017.

\begin{tabular}{llllllll}
\hline \multirow{2}{*}{ s.no } & \multirow{2}{*}{ Nutritional status } & Male & & Female & \multicolumn{3}{c}{ Total } \\
\cline { 3 - 8 } & & $\mathbf{N}(\mathbf{2 3 9})$ & $\mathbf{\%}$ & $\mathbf{N}(\mathbf{2 3 2})$ & $\mathbf{\%}$ & $\mathbf{N}(\mathbf{4 7 1})$ & $\mathbf{\%}$ \\
\hline \multirow{2}{*}{1} & Wasting (WHZ) & 33 & $13.8 \%$ & 19 & $8.2 \%$ & 52 & $11 \%$ \\
& Moderate & 26 & $10.8 \%$ & 15 & $6.5 \%$ & 41 & $8.7 \%$ \\
2 & Sever & 7 & $3 \%$ & 4 & $1.7 \%$ & 11 & $2.3 \%$ \\
3 & Under weight (WAZ) & 57 & $23.8 \%$ & 45 & $19 \%$ & 102 & $21.6 \%$ \\
\hline
\end{tabular}

When examined from the point of view of age category, the wasting was highest (26\%) among the 6-11 months of age groups and lowest (8\%) among children aged over 36 months. On the other hand, the prevalence of underweight was highest (26\%) among the 36-47 months of age groups and lowest among children aged 6-11 and 48-59 months. The highest stunting (46\%) was observed among the 24-35 months of age groups and the lowest (2.5\%) among the 6-11 months of age category (Table 5, Figure 1).

Table 5. Nutritional status of 6-59 month age children in Adi-harush and Hitsats refugee camps in Tigray region North Ethiopia 2017 by age category.

\begin{tabular}{|c|c|c|c|c|c|c|c|c|c|c|c|c|}
\hline \multirow{3}{*}{ Nutritional status } & \multicolumn{12}{|c|}{ Age group in months } \\
\hline & \multicolumn{2}{|l|}{$6-11$} & \multicolumn{2}{|l|}{$12-23$} & \multicolumn{2}{|l|}{ 24-35 } & \multicolumn{2}{|l|}{$36-47$} & \multicolumn{2}{|l|}{ 48-59 } & \multicolumn{2}{|l|}{ Total } \\
\hline & N (39) & $\%$ & N (106) & $\%$ & N (134) & $\%$ & N (101) & $\%$ & N (91) & $\%$ & $\mathrm{~N}(471)$ & $\%$ \\
\hline Wasting (WHZ) & 10 & 26 & 15 & 14 & 12 & 9 & 8 & 8 & 7 & 8 & 52 & 11 \\
\hline Moderate & 8 & 21 & 13 & 12 & 7 & 5 & 7 & 7 & 6 & 6.5 & 41 & 8.7 \\
\hline Sever & 2 & 5 & 2 & 2 & 5 & 3.7 & 1 & 1 & 1 & 1 & 11 & 2.3 \\
\hline Under weight (WAZ) & 7 & 18 & 19 & 18 & 33 & 24.6 & 26 & 26 & 17 & 18.6 & 102 & 21.6 \\
\hline Stunting (HAZ) & 1 & 2.5 & 35 & 33 & 62 & 46 & 41 & 41 & 35 & 38 & 174 & 37 \\
\hline
\end{tabular}




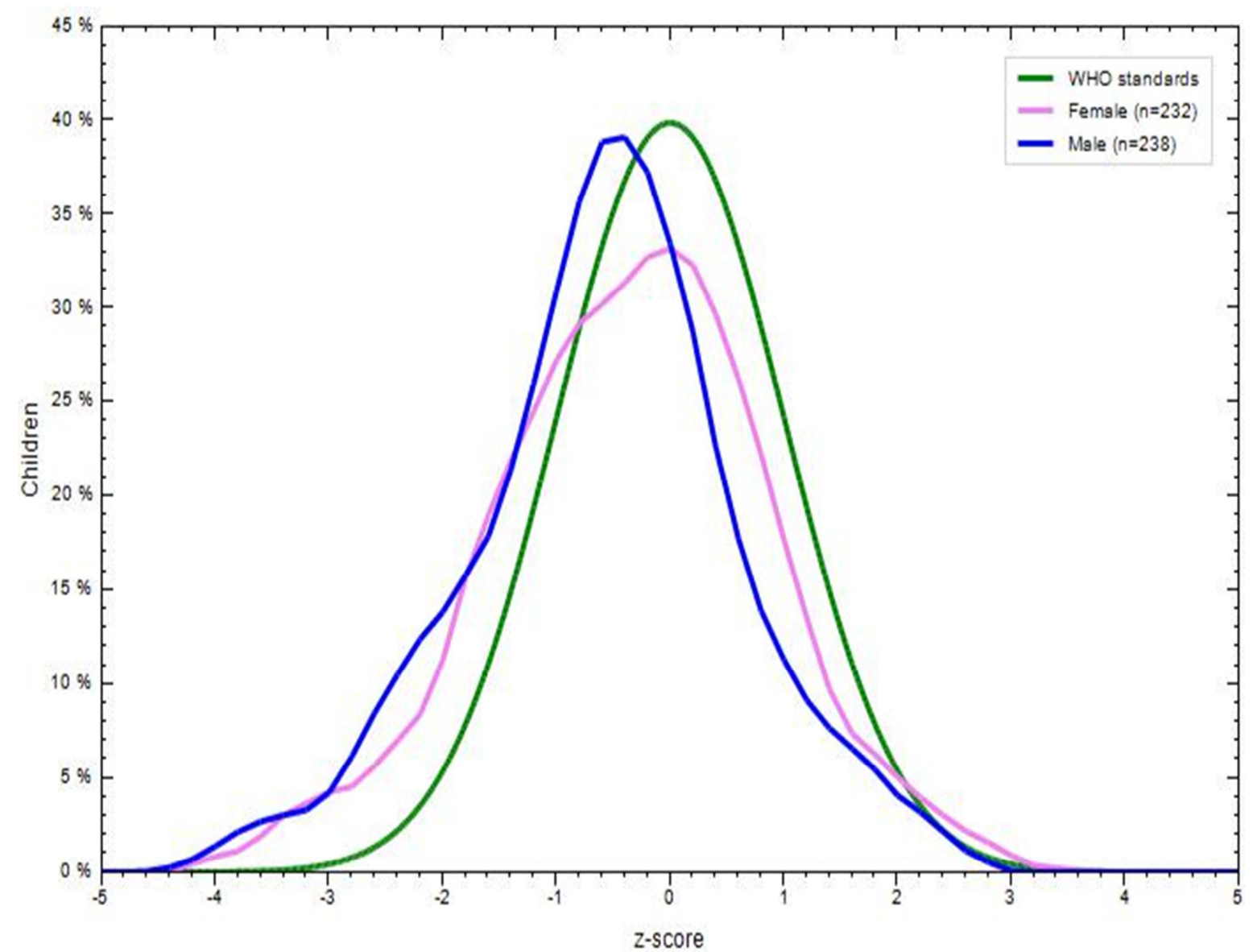

Figure 1. Graphic representation of WHZ based on sex of the children indicates that male children were slightly higher in wasting than female children in Adiharush and Hitsats refugee camps in 2017. In both sex prevalence of wasting were very high in comparison to WHO standards.

Factors associated with wasting

Both bivariate and multivariate logistic regressions were done; the result of multivariate analysis revealed that, age of child, exclusive breast feeding and feeding frequency were significantly associated with wasting. Children in the age group of $36-47$ months were $88 \%$ less likely to be wasted than children in the age group of 6-11 months $(\mathrm{AOR}=0.12$,
95\%CI: 0.03-0.39). None exclusively breastfed children were 2.51 times more likely to be wasted than those who were exclusively breast feeding children until 6 months $(\mathrm{AOR}=$ 2.51, 95\%CI: 1.17-5.40). Children who receive foods less than 3 times per day were 1.95 times more likely to be wasted than their counter parts $(\mathrm{AOR}=1.95,95 \% \mathrm{CI} 1.00$ 3.80) (Table 2).

Table 6. Factors that had association with wasting by Bivariate and multivariate analysis in Adi-harush and Hitsats Eritrean refugee camps in Tigray region North Ethiopia 2017.

\begin{tabular}{|c|c|c|c|c|c|c|}
\hline Variables name & & Wasted & Not wasted & COR 95\%CI & AOR 95\%CI & P value \\
\hline \multirow{2}{*}{ Sex of child } & Male & 33 & 206 & $1.796(0.989-3.26)$ & $1.155(0.786-3.054)$ & \multirow{7}{*}{0.004} \\
\hline & Female & 19 & 213 & 1 & 1 & \\
\hline \multirow{5}{*}{ Child age in months } & $6-11$ & 10 & 29 & 1 & 1 & \\
\hline & $12-23$ & 15 & 91 & $0.478(0.194-1.18)$ & $.29(0.11-0.82)^{*}$ & \\
\hline & $24-35$ & 12 & 122 & $0.258(0.112-0.72)$ & $.19(0.06-0.57)^{*}$ & \\
\hline & $36-47$ & 8 & 93 & $0.249(0.09-0.69)$ & $.12(0.03-0.39)^{*}$ & \\
\hline & $48-59$ & 7 & 84 & $0.242(0.084-0.69)$ & $.12(0.04-0.42)^{*}$ & \\
\hline husbands & Students And no work & 36 & 326 & $0.642(0.341-1.208)$ & $0.667(0.305-1.461)$ & \multirow{3}{*}{0.004} \\
\hline Exclusive breast feeding & Yes & 36 & 366 & 1 & 1 & \\
\hline practice & No & 16 & 53 & $3.069(1.593-5.912)$ & $2.51(1.17-5.40)$ & \\
\hline \multirow{2}{*}{ Frequency of feeding } & $<=3$ & 26 & 126 & $2.33(1.30-4.16)$ & $1.95(1.01-3.80)^{*}$ & \multirow[t]{5}{*}{0.048} \\
\hline & $>3$ & 26 & 293 & 1 & 1 & \\
\hline \multirow{2}{*}{ Vitamin A supplementation } & Yes & 41 & 378 & 1 & 1 & \\
\hline & No & 11 & 41 & $2.47(1.181-5.181)$ & $1.776(0.633-4.983)$ & \\
\hline De-worming supplementation & Yes & 28 & 297 & 1 & 1 & \\
\hline
\end{tabular}




\section{Discussion}

This study showed that, the prevalence of acute malnutrition (wasting) was $11 \%(95 \% \mathrm{CI}: 8.2-13.8)$ in the study setting with its aggravating factors. This finding was similar to that of a study conducted by IOM at the Ethiopian refugee campus (11.9\%). Moreover, EDHS 2016 and a study in Guto Gida, Oromia Region, also found a similar prevalence of 10 and $11 \%$ respectively [23-25]. The possible reason might be due to the similarity of socio economic status.

The prevalence of wasting noted in our study (11\%) was lower than the findings of studies in Dollo Ado (42\%), Shimelle District (20\%), East Bellesa (16), May-iyni refugee camp $(24.6 \%)$, and the Eritrean national wasting prevalence (15\%) [26-30]. The possible reason might be lack of adequate dietary diversity and in appropriate care of the children.

Likewise, studies conducted in IPD, Northern Uganda, Nepal, Tanzania, and Iran showed a lower prevalence of 6, 7, 6.5 and $8.19 \%$ respectively [31-34]. This may be due to, the improvements of hygienic practice; mothers may aware of child caring and program improvements like vitamin A and de-worming supplementation.

In this study, children in the age group of 48-59 months were $88 \%$ less likely to be wasted than children in $6-11$ months (AOR:.12 95\%CI 0.04-0.42). This is because younger children were more susceptible to infections than older children and may be due to the time of adaptation to complimentary feedings or sub optimal feeding practices.

None exclusively breastfed children were 2.51 times more wasted than their counter parts. This result was consistent with that of a study conducted in Saharawi Refugee Camps, Tindouf, Algeria [39]. This is due to, exclusive breast feeding until 6 month of life prevents children from infection and increases breast milk production.

According to this study, findings on feeding frequency indicate that children fed 3 and less times per day were 1.95 more likely to be wasted than those who received more than 3 times per day. This finding is in line with that of a study conducted on refugee children in Namibia [40]. This is because the more they are fed the more energy the children get.

\section{Conclusion}

This study revealed that wasting prevalence $(11 \%)$ in the study area was serious. Frequency of feeding children, exclusive breast-feeding and child age were significantly associated with wasting. Improve community health education for pregnant and lactating mothers and giving exclusive breast feeding for the children's is one of the prevention mechanisms for child wasting.

\section{Limitation of the Study}

Children born in Eritrea had no immunization cards, and the respondents might have had recall bias in telling the date of birth and age in months of children's.

\section{List of Abbreviations}

AM, Acute Malnutrition; CDR, Crude Death Rate; CM, Chronic Malnutrition; DR, Death Rate; EPHS, Eritrean Population Healthy Survey; GAM, Global Acute Malnutrition; IOM, International Organization for Migration; IDP, Internal Displaced People; IYCF, Infant and Young Children Feeding; SAM, Sever Acute Malnutrition; UNICEF, United Nation Children's Fund; WHO, World Health Organization.

\section{Declarations}

Ethics approval and consent to participate

\section{Ethical consideration}

Before commencement of the study, ethical clearance was obtained from Institutional Ethical Review board of University of Gondar. Formal letter was obtained from Adiharush and Hitsats refugee camp administrators to get permission. The first page of the questionnaire was providing full information to the study participants regarding the purpose and nature of the research. In addition, informed verbal consent and assent were obtained from each study participant to confirm willingness for participation after explaining the objective of the study. Name, personal identifiers was not including in the study. Participants' data was locked with a key/password to ensure confidentiality. Counseling on adequate nutrition and its importance was given through communicating with health workers staffs on that area for those whose child is malnourished.

Consent to publish

Not applicable

Availability of Data and Materials

Data will be made available upon requesting the primary author

\section{Competing Interests}

All the authors do not have any possible conflicts of interest.

\section{Funding}

No funding was obtained for this study

\section{Author's Contribution}

Conceived and designed the experiments: BM, HYY, HB and KAG. Performed the experiments: HB. Analyzed the data BM, HYY, HB and KAG: Wrote the paper: BM, HYY, $\mathrm{HB}$ and KAG. Approved the proposal with some revisions: BM, HYY, HB and KAG.

\section{Acknowledgements}

We are thankful to children, interviewed families, data collectors and supervisors of this study. 


\section{References}

[1] Black, R. E., et al., Maternal and child undernutrition: global and regional exposure and health consequences. Lancet, 2008. www.thelancet.com.

[2] Jones, G., et al., How many child deaths can we prevent this year? Lancet, 2003. 362: p. 65-71.

[3] report, G.n.c., Acute malnutrition in everyday emergency under five children 2014.

[4] IASC, USAID, the Harmonised Training Package (HTP): Resource Material for Training on Nutrition in Emergencies, Version 2 (2011).

[5] Habtom Kelati, et al., Prevalence of Acute Malnutrition and its Associated Factors among Children aged 6-59 months in MaiAini Eritrean Refugees' Camp, Northern Ethiopia. Nutrition and Food Sciences, 2014. 5 (1).

[6] Shash, H. A., The Nutritional Status of Populations in Refugee/Internally Displaced Camps that Include Refugees from the Same National Origin as Refugees in DeKalb County, GA. 2011, Emory University.

[7] UNICEF (2011) The global average rate of children under five years of age who are underweight was $16 \%$.

[8] EDHS (2016) Demographic and Health Survey, Preliminary Report. Ethiopia. Available ICF Macro Calverton, Maryland, USA.

[9] World Health Organization (2000) Turning the tides of Malnutrition; Responding to the Challenges of 21 st Century. CH-1211, WHO, Geneva.

[10] B. Holaday, S. David, and M. L. Lobo, "Childhood diarrhea andmalnutrition in Pakistan, part I: incidence and prevalence," Journal of Pediatric Nursing, vol. 10, no. 2, pp. 131-137, 1995.

[11] G. Pechlaner and G. Otero, "The neoliberal food regime: neoregulation and the new division of labor in North America," Rural Sociology, vol. 75, no. 2, pp. 179-208, 2010.

[12] R. E. Black, L. H. Allen, Z. A. Bhutta et al., "Maternal and child undernutrition: global and regional exposures and health consequences,"TheLancet, vol. 371, no. 9608, pp. 243-260, 2008.

[13] C. G. Victora, L. Adair, C. Fall et al., "Maternal and child undernutrition: consequences for adult health and human capital," The Lancet, vol. 371, no. 9609, pp. 340-357, 2008.

[14] J. Currie and D. Almond, "Human capital development before age five," Handbook of Labor Economics, vol. 4, pp. 13151486, 2011.

[15] R. Martorell, P. Melgar, J. A. Maluccio, A. D. Stein, and J. A. Rivera, "The nutrition intervention improved adult human capital and economic productivity," The Journal of Nutrition, vol. 140, no. 2, pp. 411-414, 2010.

[16] K. G. Dewey and K. Begum, "Long-termconsequences of stunting in early life," Maternal and Child Nutrition, vol. 7, no. 3, pp. 5-18, 2011.

[17] S. Grantham-McGregor, Y. B. Cheung, S. Cueto, P. Glewwe, L. Richter, and B. Strupp, "Developmental potential in the first 5 years for children in developing countries," The Lancet, vol. 369 , no. 9555 , pp. 60-70, 2007.
[18] R. Martorell, B. L. Horta, L. S. Adair et al., "Weight gain in the first two years of life is an important predictor of schooling outcomes in pooled analyses from five birth cohorts from lowandmiddle-income countries," The Journal of Nutrition, vol. 140, no. 2, pp. 348-354, 2010.

[19] Resolution WHA65.6. Comprehensive implementation plan on maternal, infant and young child nutrition. In: Sixty-fifth World Health Assembly Geneva, 21-26 May 2012. Resolutions and decisions, annexes. Geneva: World Health Organization; 2012: $12-13 \quad$ (http://www. who.int/nutrition/topics/WHA65.6_resolution_en.pdf?ua=1, accessed 6 October 2014).

[20] World Health Organization. Global targets 2025. To improve maternal, infant and young child nutrition (www.who.int/nutrition/topics/nutrition_globaltargets2025/en/, accessed 6 October 2014).

[21] EDHS (2011) Demographic and Health Survey, Preliminary Report. Ethiopia. Available ICF Macro Calverton, Maryland, USA.

[22] Fentahun, W., M. Wubshet, and A. Tariku, Undernutrition and associated factors among children aged 6-59 months in East Belesa District, northwest Ethiopia: a community based cross-sectional study. BMC public health, 2016. 16 (1): p. 506.

[23] International Organization for Migration, nutrition surveillance report issue no. 2, January-December 2011.

[24] Alemu Adeba1, Dr. Sileshi Garoma2, Habtamu Fekadu, Wondu Garoma2 Prevalence of Wasting and Its Associated Factors of Children among 6-59 Months Age in Guto Gida District, Oromia Regional state, Ethiopia. Vol 24, 2014.

[25] USID, Unicef, WORLD BANK the Global Fund and Federal Democratic Republic of Ethiopia demographic and health survey 2016.

[26] Solomon Demissie, Amare Worku Magnitude and factors associated with malnutrition in children 6-59 months of age in pastoral community of Dollo Ado district, Somali region, Ethiopia, 2013.

[27] Abdibari Ma'alin1, Dereje Birhanu2, Samuel Melaku3, Daniel Tolossa4*, Yusuf Mohammed5 and Kiros Gebremicheal1 Magnitude and factors associated with malnutrition in children 6-59 months of age in Shinille Woreda, Ethiopian Somali regional state: a cross-sectional study, 2016.

[28] Wagaye Fentahun1, Mamo Wubshet2 and Amare Tariku Undernutrition and associated factors among children aged 659 months in East Belesa District, northwest Ethiopia, 2016.

[29] Habtom Kelati, Bezatu Mengiste, Tadesse Alemayehu and Bereket Damtew prevalence of acute malnutrition and its associated factors among children aged 6-59 months in Maiaini Eritrean refugees' camp, Northern Ethiopia published November 17, 2014.

[30] United Nations Children's Fund, draft country program document Eritrea 21 June 2016.

[31] Mary Abwola Olwedo1, Edison Mworozi1, Hanifa Bachou1, Christopher Garimoi Orach2 factors associated with malnutrition among children in internally displaced person's camps, Northern Uganda African health sciences vol 8 no 4 December 2008. 
[32] Chataut J, Khanal K Assessment of Nutritional Status of Children under Five years of age in rural Nepal vol. 14, 2016.

[33] John G. Safari, Zacharia S. Masanyiwa and 1 James E. Lwelamira Prevalence and Factors Associated with Child Malnutrition in Nzega District, Rural Tanzania, 2015.

[34] Elham Kavosi, Zahra Hassanzadeh Rostami, Zahra Kavosi, Aliasghar Nasihatkon, Mohsen Moghadami, Mohammadreza Heidari Prevalence and determinants of under-nutrition among children under six: a cross-sectional survey in Fars province, Iran, 2014.

[35] Solomon Demissie, Amare Worku Magnitude and factors associated with malnutrition in children 6-59 months of age in pastoral community of Dollo Ado district, Somali region, Ethiopia, 2013.

[36] Alemu Adeba, Dr. Sileshi Garoma, Habtamu Fekadu, Wondu Garoma Prevalence of Wasting and Its Associated Factors of
Children among 6-59 Months Age in Guto Gida District, Oromia Regional state, Ethiopia. Vol 24, 2014.

[37] Habtom Kelati, Bezatu Mengiste, Tadesse Alemayehu and Bereket Damtew prevalence of acute malnutrition and its associated factors among children aged 6-59 months in Maiaini Eritrean refugees' camp, Northern Ethiopia published November 17, 2014.

[38] Unicef-WHO-the World Bank Joint child malnutrition estimates, levels \& trends in child malnutrition 2012.

[39] WFP, UNHCR Report on Nutrition Survey and Anemia Intervention Impact Analysis May, 2013.

[40] Prof. David Sanders An evaluation of the nutritional status of refugee children in Namibia 2004. 